\title{
Tratamentos para obtenção de TaC em superfície de grafite. Parte I: Imersão em Solução Aquosa de $\mathrm{TaF}_{7}^{2-}$
}

\author{
(TaC formation on graphite surface. \\ Part I: Immersion in aqueous solution of $\left.\mathrm{TaF}_{7}{ }^{2-}\right)$
}

\author{
H. J. Izário Fo 1, F. Vernilli Jr. ${ }^{2}$, D. V. B. S. Pinto ${ }^{3}$, N. Baccan ${ }^{4}$, A. F. Sartori ${ }^{2}$ \\ ${ }^{1}$ Departamento de Engenharia Química - FAENQUIL \\ ${ }^{2}$ Departamento de Engenharia de Materiais - FAENQUIL \\ C. P. 116, 12600-000, Lorena, SP. \\ vernilli@demar.faenquil.br \\ ${ }^{3}$ Instituto de Química da Universidade de S. Paulo - USP \\ ${ }^{4}$ Instituto de Química da Universidade de Campinas - UNICAMP
}

\begin{abstract}
Resumo
A espectrometria de absorção atômica com atomização eletrotérmica em forno de grafite, como método analítico, possui uma grande vantagem que é a sensibilidade na detecção, tendo assim grande aceitação como rotina analítica em laboratórios de aplicação e pesquisa. Apesar desta metodologia possuir grande poder de detecção, sua aplicação é limitada pelo custo de operação e pela interação química de alguns elementos com a superfície do tubo de grafite. Este trabalho apresenta uma metodologia para obtenção de uma camada de carbeto de tântalo na superfície do grafite, cujas propriedades permitem a atomização do analito sem interferência da camada formada. A metodologia apresentada neste trabalho é a imersão do tubo de grafite em solução aquosa de $\mathrm{TaF}_{7}{ }^{2-}$. Os corpos de prova obtidos foram submetidos a tratamentos térmicos para a formação do carbeto de tântalo. A homogeneidade das camadas formadas e suas morfologias foram acompanhadas por microscopia eletrônica de varredura e a formação do carbeto de tântalo foi confirmada por difratometria de raios X.
\end{abstract}

Palavras-chave: carbeto de tântalo, grafite, eletrodeposição.

\section{INTRODUÇÃO}

No estado da arte para a determinação de impurezas metálicas em metais com alta pureza, a espectrometria de absorção atômica com atomização eletrotérmica destaca-se como uma boa técnica para a determinação em metais refratários. Esta técnica permite atomizar amostras em tubos de grafite aquecidos em torno de $3000^{\circ} \mathrm{C}$, tornando o método altamente sensível e capaz de determinar traços de um grande número de elementos, diretamente em matrizes de diversas amostras $[3,4]$.

Quando se trata de análise de metais refratários em forno de grafite, trabalhando a altas temperaturas, podem ocorrer inúmeras

\begin{abstract}
The atomic absorption spectrometry with electrothermal atomization in graphite oven, as an analytical method, possesses a great advantage of high sensibility detection; due to this advantage, it has been largely accepted as an analytical routine in application and research laboratories. In spite of its large detection power, the application of this methodology is limited by the operation cost and by the chemical interaction of some elements with the graphite tube surface. This work presents the methodologies of formation of tantalum carbide in the surface of graphite tubes by immersion of the graphite tube in aqueous solution of $\mathrm{TaF}_{7}{ }^{2-}$. The samples obtained following this methodology were thermally treated in order to obtain the tantalum carbide. The homogeneity of the formed layers and their morphologies were characterized by scanning electron microscopy; the formation of tantalum carbide was confirmed by $X$-ray diffraction.
\end{abstract}

Keywords: tantalum carbide, graphite, electrodeposition.

interferências à formação de carbeto entre o metal majoritário e o material do tubo. Desta forma, para se determinar as impurezas metálicas de interesse na presença da matriz de um elemento cuja cinética química tende a formar carbeto metálico, é necessário realizar um tratamento superficial nos tubos de grafite, de maneira adequada, para que não haja interação química entre o grafite do tubo e o elemento majoritário da matriz analisada [1].

Há dois tipos de tubos de grafite fornecidos pelo fabricante Perkin Elmer: o tubo revestido piroliticamente, que possui uma superfície extremamente homogênea (lisa), impermeável a vapores ou solventes e contrariamente, os tubos sem revestimento pirolítico que possuem superfície irregular e escamosa, com menor densidade 
e custo inferior ao revestido piroliticamente [2].

Embora o tubo com tratamento pirolítico possua propriedades morfológicas que o destaca analiticamente, estas características não impedem a formação da camada de carbeto na presença de metais refratários (Mo, $\mathrm{Nb}, \mathrm{Ta}$, e outros), sob aquecimento. $\mathrm{O}$ tratamento da superfície de tubos de grafite ("coatings") tem sido utilizado para aumentar a sensibilidade e a vida útil do tubo em relação ao número de atomizações, mantendo boa reprodutibilidade nos resultados [3]. Desta forma, a impregnação do grafite com os elementos $\mathrm{W}, \mathrm{Zr}, \mathrm{Ta}, \mathrm{Nb}$ e Mo, que formam carbetos estáveis e de alto ponto de fusão, altera favoravelmente as características da superfície do grafite através da competição pelos sítios ativos livres do carbono [4]. Esta modificação com carberto de tântalo na superfície dos tubos de grafite foi aplicada no desenvolvimento de uma metodologia analítica para a determinação de impurezas metálicas em amostras de tântalo com alta pureza, utilizando-se a espectrometria de absorção atômica com atomização eletrotérmica em forno de grafite. Portanto, como todos os carbetos formados, provenientes destes elementos refratários mencionados anteriormente, possuem propriedades similares quanto a esta aplicação específica, optou-se pelo carbeto de tântalo pelo fato da amostra ser tântalo e, também, evitar interferências analíticas com o emprego de outros elementos. Diversos trabalhos publicados citam métodos de tratamentos de superfícies que envolvem metodologias simples, como a imersão do tubo em solução do metal de interesse e posterior tratamento térmico no próprio forno de grafite [5], e outros mais específicos como a eletrólise em meio de sais fundidos [6].

Analiticamente, caracteriza-se como boa camada de carbeto de tântalo, aquela que apresenta superfície lisa (sem poros), homogênea em toda a extensão do tubo e com espessura adequada para não comprometer seu aquecimento. Nestas condições, o tubo revestido apresentará boa performance analítica durante a atomização do analito.

Neste trabalho será apresentada a metodologia de imersão do tubo de grafite em solução de tântalo, que possibilita, após tratamento térmico, a formação de carbeto de tântalo sobre a superfície do tubo de grafite. A formação de carbeto de tântalo foi acompanhada por difratometria de raios X e a camada formada foi avaliada pela sua homogeneidade e morfologia dos grãos, através

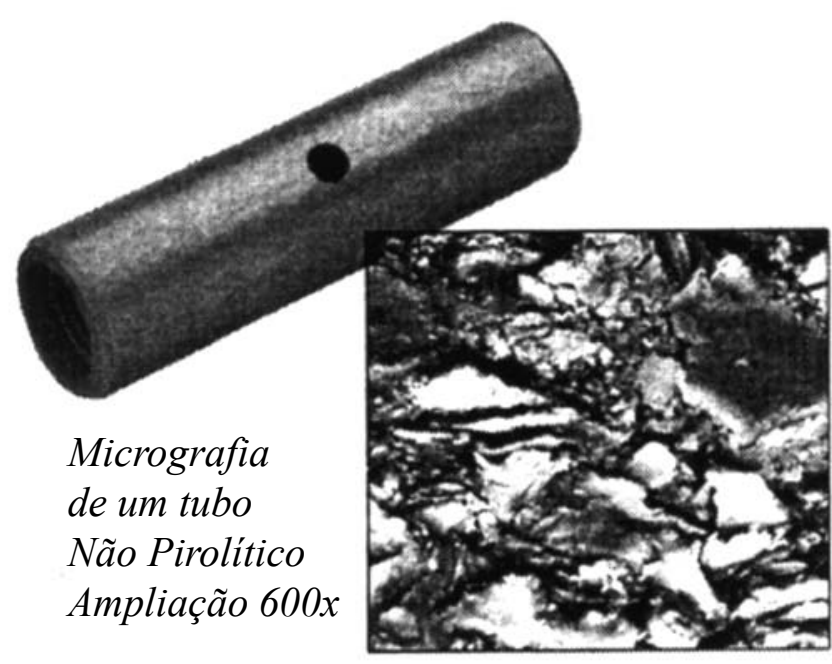

Figura 1: Tubos de grafite fornecidos pela Perkin Elmer [2]. [Figure 1: Perkin Elmer graphite tubes [2].] de observação por microscopia eletrônica de varredura (MEV).

\section{EXPERIMENTAL}

Para este estudo experimental foram utilizados como corpos de prova, tubos de grafite com $6 \mathrm{~mm}$ de diâmetro interno e $28 \mathrm{~mm}$ de comprimento, com $1 \mathrm{~mm}$ de espessura de parede. Há dois tipos de tubos de grafite fornecidos pelo fabricante Perkin Elmer: o tubo revestido e o sem revestimento pirolítico.

Tubos de grafite piroliticamente revestidos são feitos de pureza espectral, com grafite de alta densidade, revestidos com uma camada extremamente pura de grafite depositado piroliticamente com superfície extremamente homogênea (lisa) e densa (baixa porosidade). Contrariamente, os tubos sem revestimento pirolítico possuem superfície irregular e escamosa, com custos bem menores comparados aos revestidos piroliticamente. A Fig. 1 mostra as micrografias dos tubos com e sem revestimento pirolítico [2].

Embora o tubo com tratamento pirolítico possua propriedades morfológicas que o destaca analiticamente, essas características não impedem a formação da camada de carbeto na presença de metais refratários (Mo, $\mathrm{Nb}$, Ta e outros), sob aquecimento.

Uma das vantagens em revestir com carbeto a superfície de grafite é a de melhorar as características físico-químicas, apresentadas em relação à superfície pirolítica: formação de uma camada extremamente homogênea, densa, inerte e resistente química e termicamente [5].

Assim sendo, torna-se viável a utilização de tubos de grafite não pirolítico, para que se proceda um tratamento de sua superfície, e utilizá-lo para fins analíticos específicos e, também, pelo seu valor comercial. Portanto, todos os ensaios realizados neste trabalho, utilizaram-se tubos sem revestimento pirolítico.

Todos os reagentes utilizados neste trabalho foram de pureza analítica (P.A.).

A metodologia testada consistiu na imersão do tubo em uma solução de tântalo e posterior tratamento térmico, possibilitando a formação da camada de carbeto na superfície do grafite. Inicialmente, realizou-se um ensaio semelhante ao que foi descrito por Zatka [7], no qual um tubo de grafite foi imerso em uma solução a $6 \% \mathrm{~m} / \mathrm{v}$ de tântalo, em meio fortemente fluorídrico, na presença

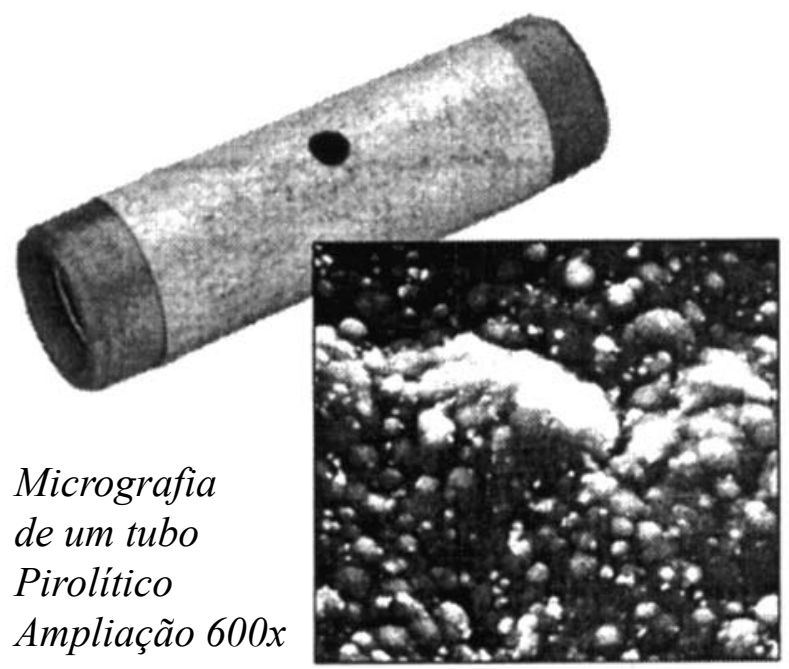


de ácido oxálico e de peróxido de hidrogênio como agente oxidante, sob baixo vácuo, deixando-o 30 segundos submerso. Decorrido este tempo, o tubo foi seco, primeiramente, com ar a $\approx 50{ }^{\circ} \mathrm{C}$ e posteriormente, em estufa a $105^{\circ} \mathrm{C}$ durante uma hora.

Para a formação da camada de carbeto, fez-se o tratamento térmico no próprio forno de grafite do aparelho de absorção atômica utilizado para desenvolver todas as metodologias analíticas, cujo modelo do espectrômetro é o 4000 da Perkin ELmer equipado com um forno de grafite HGA-400 e um amostrador automático AS-40 [7].

A Fig. 2 mostra esquematicamente o forno de grafite, tendo seu fechamento pneumático, refrigerado com água e por vazão de argônio interno e externamente ao tubo, com aquecimento resistivo controlado por um sensor ótico de temperatura. O tubo de grafite é colocado dentro do forno, alinhado por uma ferramenta que o ajusta perfeitamente ao forno. A programação de aquecimento permite até oito etapas, podendo atingir até $3000^{\circ} \mathrm{C}$ e permanecer durante $5 \mathrm{~s}$ nesta temperatura.

O tubo de grafite é colocado dentro do forno, alinhado por uma ferramenta que o ajusta perfeitamente ao forno. A programação de aquecimento foi realizada em dois estágios: $30 \mathrm{~s}$ até $1000^{\circ} \mathrm{C}$ e 10 segundos até $2500^{\circ} \mathrm{C}$.

Após estudar a performance da metodologia usada por Zatka, procurou-se otimizar todo o processo, testando-se variáveis como tempo de imersão, temperatura da solução de imersão e ciclo do tratamento térmico.

Para otimização do tempo de imersão do tubo de grafite não pirolítico usou-se como parâmetro significativo a homogeneidade da camada de carbeto de tântalo formada, após tratamento térmico, em toda a extensão do tubo.

Como a permeabilidade do grafite é muito baixa, a inadequada aderência do carbeto de tântalo à superfície do tubo, pode estar relacionada com a espessura da camada formada durante a imersão. Isto nos levou a estudar o comportamento da formação da camada

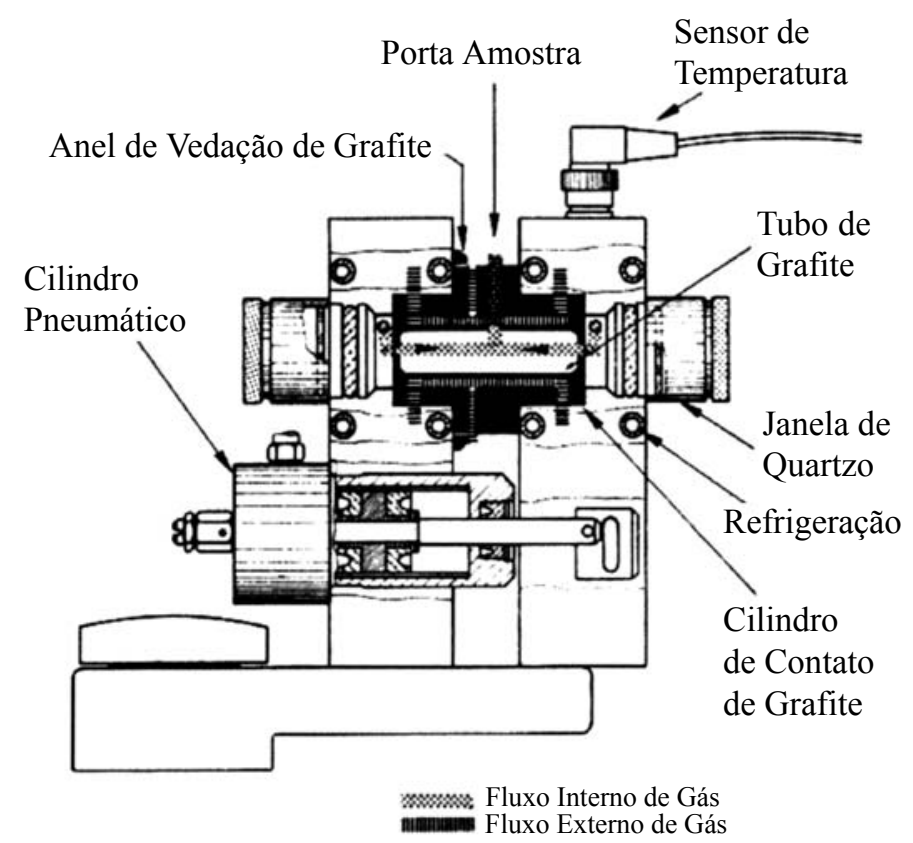

Figura 2: Esquema geral do forno de grafite do equipamento de Absorção Atômica 4000 da Perkin Elmer [7].

[Figure 2: General outline of the graphite furnace of the model 4000 Perkin Elmer Atomic Absorption equipment [7].]

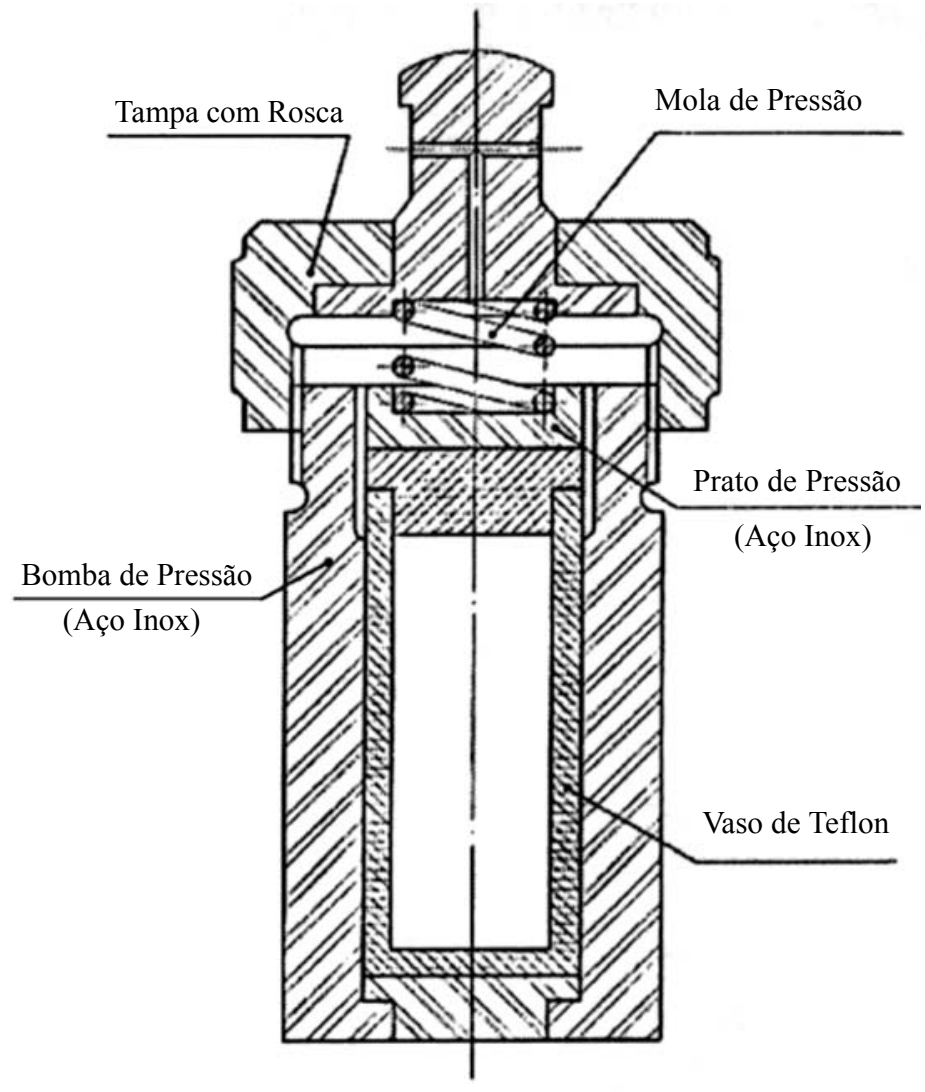

Figura 3: Esquema geral da bomba de decomposição.

[Figure 3: Cross section view of the decomposition bomb.]

de carbeto, variando os tempos de imersão e a temperatura da solução. Os tempos de imersão do tubo de grafite em solução de tântalo estudados foram de 4, 8, 12, 16 e 20 horas à temperatura ambiente $\left(25^{\circ} \mathrm{C}\right)$ e de 24 horas à temperaturas de 25,50 e $100^{\circ} \mathrm{C}$.

Basicamente, esta metodologia consistiu em imergir o tubo na solução de tântalo contida em uma cápsula de teflon, sendo esta adaptada a uma bomba de decomposição com aquecimento controlado (Fig. 3). Após a imersão, o tubo foi seco com ar $\mathrm{a} \approx 50^{\circ} \mathrm{C}$ $\mathrm{e}$, em seguida, a $105^{\circ} \mathrm{C}$ em estufa durante $1 \mathrm{~h}$. Posteriormente, o tubo foi acoplado ao forno de grafite para o tratamento térmico.

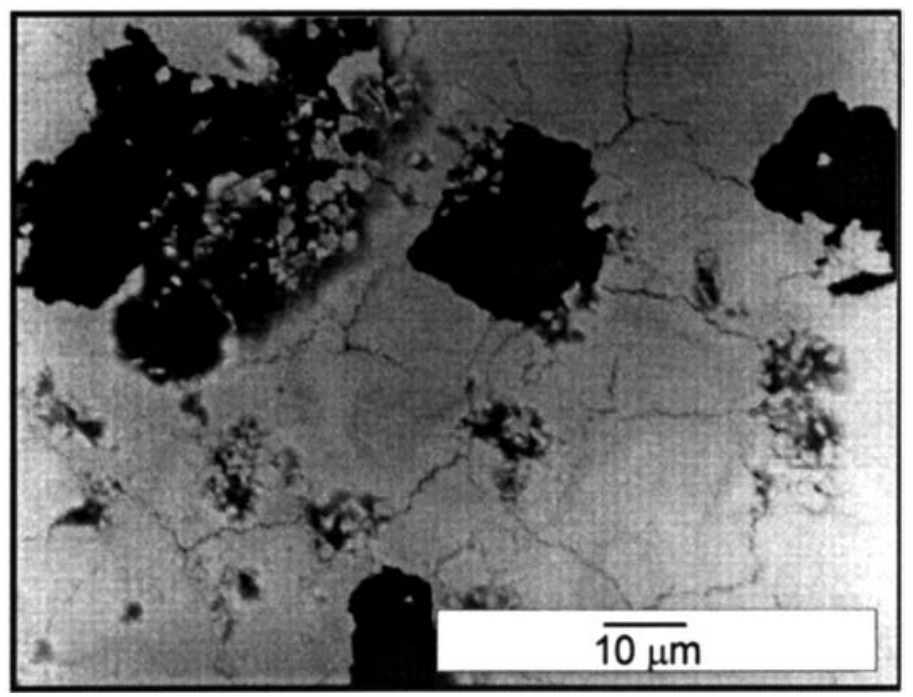

Figura 4: Micrografia do carbeto de tântalo, obtida através do método de Zatka. [Figure 4: Micrograph of tantalum carbide, obtained after method of Zatka.] 


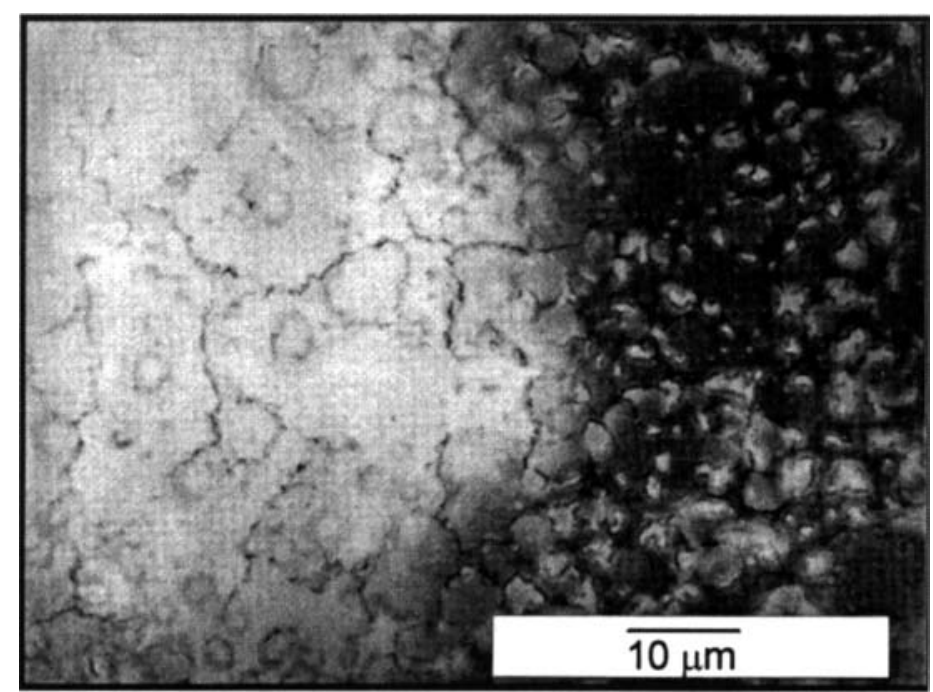

Figura 5: Microestrutura do carbeto de tântalo obtido pelo processo de imersão a $25{ }^{\circ} \mathrm{C}$ durante 24 horas.

[Figure 5: Microstructure of the tantalum carbide obtained by the immersion process at $25^{\circ} \mathrm{C}$ for 24 hours.]

A formação da camada de carbeto de tântalo foi confirmada por análise de difração de raios X e sua homogeneidade e a morfologia dos grãos foram avaliadas através de microscopia eletrônica de varredura. Para realizar as análises microscópicas, os tubos tratados termicamente foram cortados longitudinalmente e, posteriormente, transversalmente.

\section{RESULTADOS E DISCUSSÃO}

O tratamento térmico do tubo de grafite imerso em solução de tântalo em meio ácido oxálico, aqui realizado conforme descrito por Zatka, forneceu como resultado um tubo com uma camada superficial de coloração amarelo-ouro, característica do carbeto de tântalo [8]. A micrografia da Fig. 4, obtida por MEV, apresenta falhas na camada de carbeto de tântalo, identificadas pelas regiões escuras, o que caracteriza pouca aderência sobre a superfície do grafite, apresentando também trincas, provavelmente devido a tensões térmicas, desqualificando, portanto este revestimento para fins analíticos específicos.

Após avaliar a performance da metodologia usada por Zatka, procurou-se otimizar todo o processo, uma vez que o tubo obtido neste procedimento não apresentou resultados similares aos descritos em seu trabalho. Alguns resultados experimentais mostraram que variáveis como o tempo e a temperatura são fundamentais para obter uma camada de carbeto homogênea, contrariando aos parâmetros usados por Zatka como temperatura ambiente e 30 s de imersão.

O tempo ótimo, usando uma solução a $6 \% \mathrm{~m} / \mathrm{v}$ de tântalo à temperatura ambiente, ficou acima de 16 horas. Macroscopicamente, a superfície da camada do carbeto de tântalo sobre a superfície do tubo de grafite apresentou homogeneidade e aderência. A micrografia da Fig. 5 não apresenta falhas na camada de carbeto, porém, podem ser observadas trincas na camada superficial, o que sugere a necessidade de uma otimização na metodologia testada.

As Figs. 6a e 6b mostram as micrografias das partes internas dos tubos obtidos após imersão realizada a 50 e a $100{ }^{\circ} \mathrm{C}$, respectivamente. Nos dois casos, após tratamento térmico, houve (a)

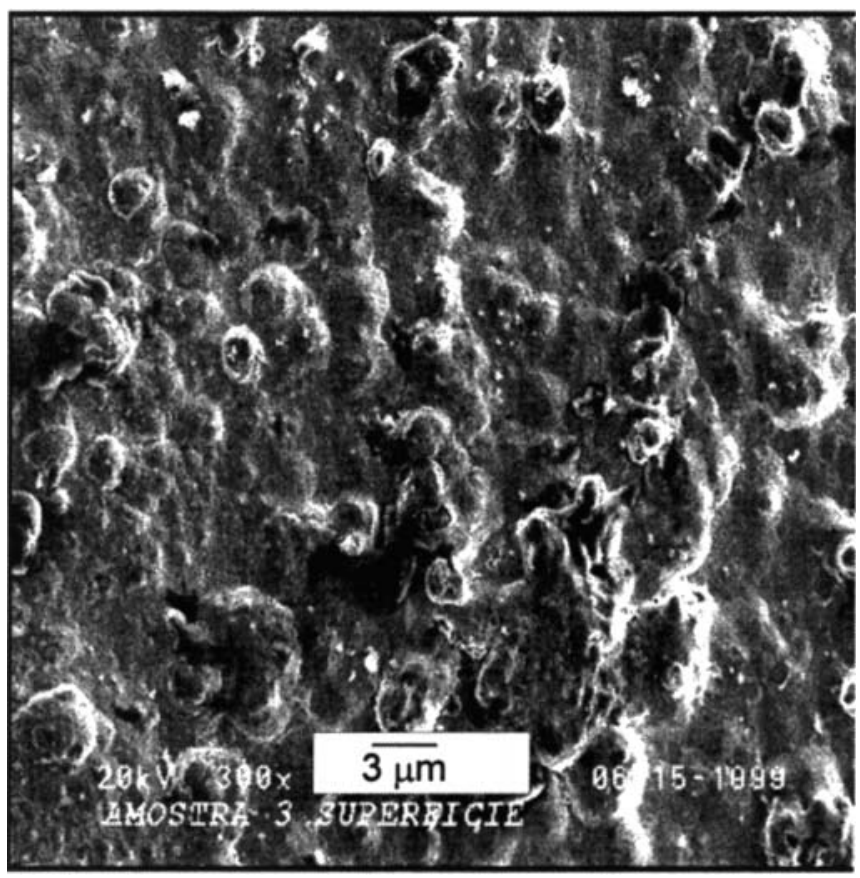

(b)

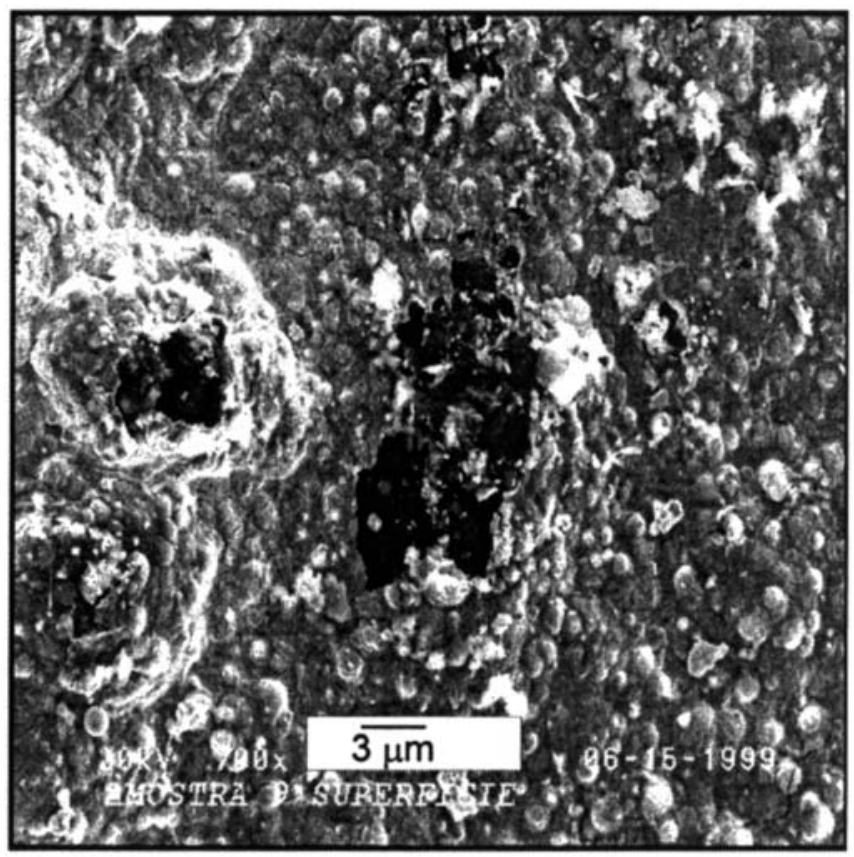

Figura 6: Micrografias do carbeto de tântalo formado pela imersão em solução durante 24 horas: (a) a $50^{\circ} \mathrm{C}$ e (b) a $100{ }^{\circ} \mathrm{C}$.

[Figure 6: Micrographs of the tantalum carbide formed by the immersion in solution for 24 hours: (a) at $50^{\circ} \mathrm{C}$ and (b) at $100^{\circ} \mathrm{C}$.]

formação de grãos nodulares, contudo, com imersão realizada a $100{ }^{\circ} \mathrm{C}$ a superfície do tubo não ficou homogênea, apresentando falhas.

Nas micrografias das Figs. 7a e 7b pode-se observar a seção transversal característica da camada de carbeto de tântalo formada, para a temperatura de $50{ }^{\circ} \mathrm{C}$ e $100{ }^{\circ} \mathrm{C}$, respectivamente, sendo a espessura da camada de $\approx 35 \mu \mathrm{m}$ para $50^{\circ} \mathrm{C} \mathrm{e} \mathrm{de} \approx 60 \mu \mathrm{m}$ para $100^{\circ} \mathrm{C}$. A Fig. 8 apresenta o difratograma de raios $\mathrm{X}$ característicos do método estudado, onde se pode confirmar a formação de carbeto de tântalo. Em todos os testes realizados as amostras apresentaram a mesma curva de difratometria de raios $\mathrm{X}$. 
(a)

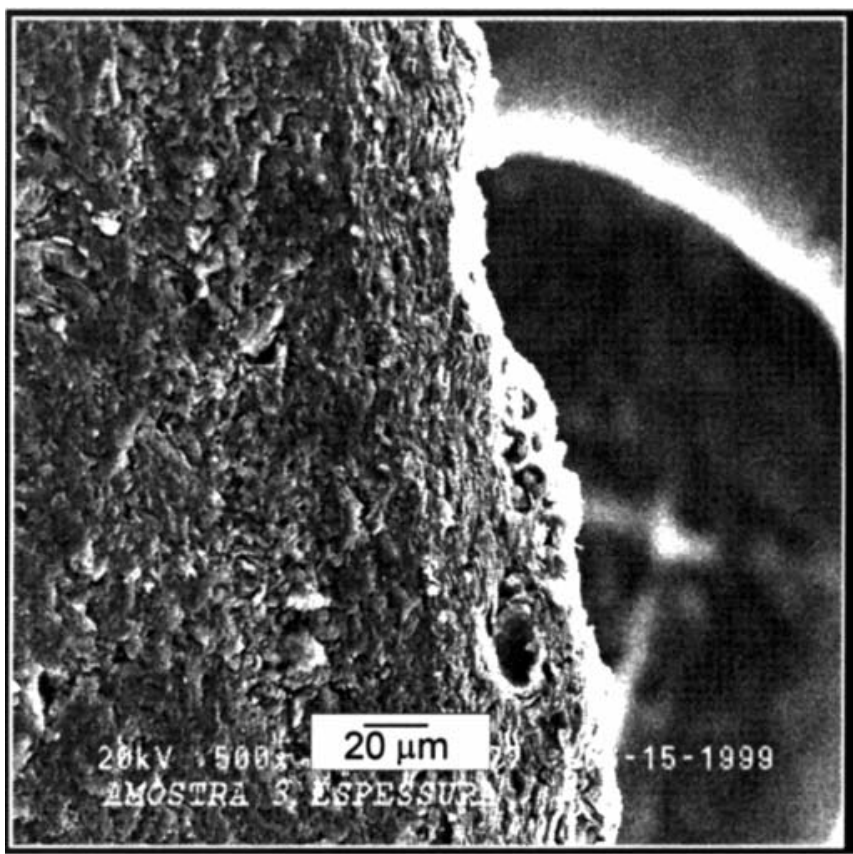

(b)

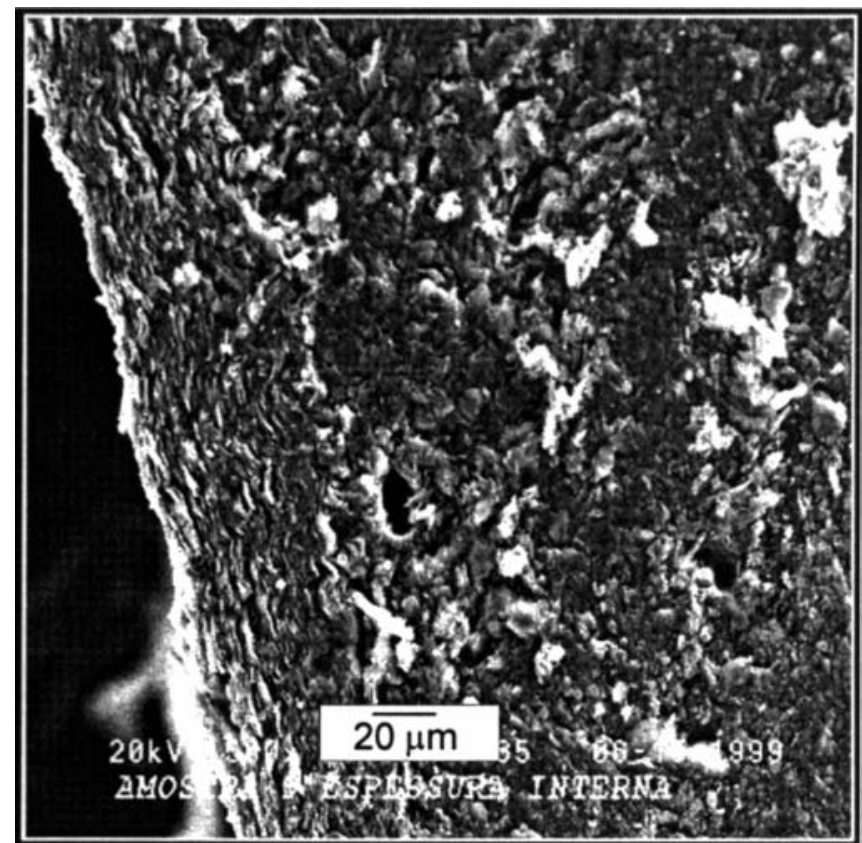

Figura 7: Micrografia da camada de carbeto de tântalo formada a $50{ }^{\circ} \mathrm{C}$ pela imersão em solução durante 24 horas: (a) a $50{ }^{\circ} \mathrm{C}$ e (b) a $100{ }^{\circ} \mathrm{C}$. [Figure 7: Micrographs of tantalum carbide layer formed at $50^{\circ} \mathrm{C}$ by immersion in solution for 24 hours: (a) at $50^{\circ} \mathrm{C}$ and (b) at $100^{\circ} \mathrm{C}$.]

\section{CONCLUSÕES}

Inicialmente, os testes utilizando o procedimento de Zatka, imersão em solução de tântalo na presença de ácido oxálico e baixo vácuo, mostrou-se deficiente quanto à formação da camada de carbeto de tântalo, pois acarretou falhas e trincas nessa superfície. Os melhores resultados foram obtidos com imersão do tubo em

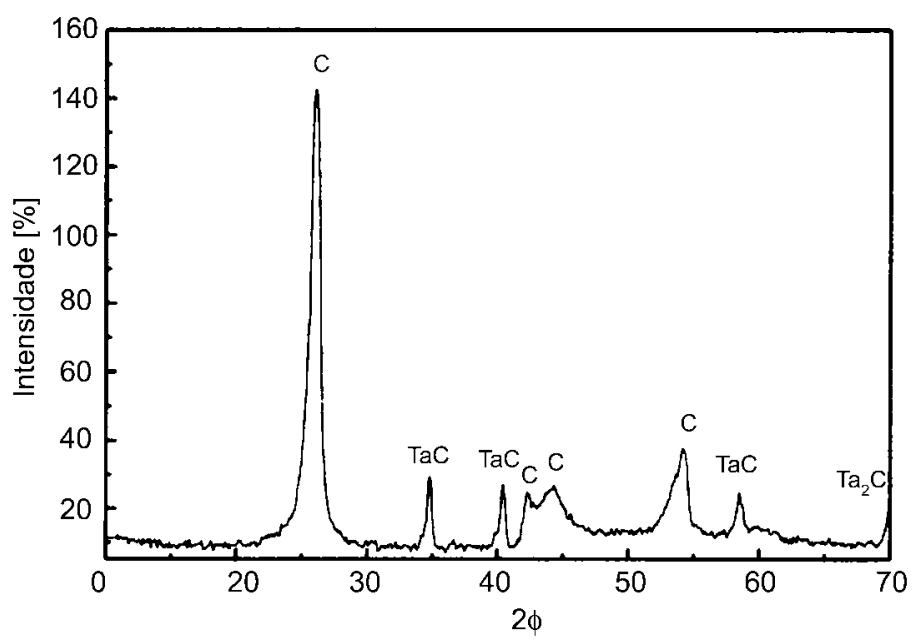

Figura 8: Análise de difração de raios $\mathrm{X}$ do carbeto formado pela imersão em solução de Ta a $100{ }^{\circ} \mathrm{C}$ por 24 horas.

[Figure 8: X-ray diffraction analysis of the carbide formed by immersion in solution of Ta at $100^{\circ} \mathrm{C}$ for 24 hours.]

solução a $50^{\circ} \mathrm{C}$ para tempo acima de 16 horas. Isto comprova, que existe um valor ideal de temperatura da solução e de tempo de imersão, que facilita a penetração superficial da solução de tântalo no grafite, sem que ocorra comprometimento do tubo revestido. Nestas condições foi possível obter tubos revestidos com uma camada homogênea em toda a sua extensão, com superfície lisa, boa aderência sobre o grafite, morfologia nodular e espessura característica de $\approx 35 \mu \mathrm{m}$.

\section{REFERÊNCIAS}

[1] A. B. Volysky, "Terminology for the modification of graphite tubes with hight-melting carbides used in eletrothermal atomic absorption spectrometry", Spectrochim. Acta. 8, 50 (1995) 1417-19. [2] Perkin Elmer Atomic Spectroscopy Supplies Catalog. (1995/96). [3] A. B. Volysky, E. M. Sedykh, "Principal processes in graphite atomisers modified by high-melting carbides", J. Anal. At. Spectrom. 4 (1989) 71-76.

[4] M. R. A. Michaelis, W. Wegscheider, H. M. Ortner, "Tantalum carbide coated platforms for atomic absorption spectrometry with electrothermal atomization: performance characteristics for tin, selenium and rhodium", J. of Analyt. Atom. Spectrometry 3 (1988) 503-509.

[5] V. J. Zatka, "Tantalum treated graphite atomizer tubes for atomic absorption spectrometry", Anal. Chem. 50, 3 (1978) 538-541.

[6] G. W. Mellors, S. Senderoff, "Electrodeposition of coherent deposits of refractory metals. I - Niobium", J. Electrochem. Soc. 112 (1995) 266-72.

[7] R. D. Beat, "Concepts, instrumentation and techniques in atomic absorpition espectrofotometry", Perkin-Elmer Co. (1978).

[8] G. S. Brady, Materials Handbook, Mc Graw-Hill Book Company (1971).

(Rec. 26/10/1999, Rev. 03/04/2001, Ac. 20/04/2001) 